\title{
VIOLÊNCIA, JUVENTUDES E EDUCAÇÃO: UMA LEITURA SOBRE CONSTRUÇÕES DISCURSIVAS
}

\author{
Valentina Carranza Weihmuller \\ Universidade Federal do Rio de Janeiro (UFRJ), Rio de Janeiro, RJ, \\ Brasil \\ Vera Helena Ferraz de Siqueira \\ Universidade Federal do Rio de Janeiro (UFRJ), Rio de Janeiro, RJ, \\ Brasil \\ ANDREA Costa da Silva \\ Universidade da Força Aérea (UNIFA), Rio de Janeiro, RJ, Brasil
}

Resumo: O artigo lança mão do enquadramento de vertentes socioantropológicas e pós-estruturalistas para discutir/tensionar a noção de violência, evidenciando-a como narrativa, instituidora de "regimes de verdades". Aborda, nessa mesma perspectiva, as estatísticas produzidas pelo Estado e faz uma análise de "textos" no campo da educação em saúde, caracterizando-os como estratégias discursivas de saber-poder, monopolizadas pelos aparelhos midiáticos, que funcionam como norteadores dos campos de ação e das prioridades das políticas públicas, ao mesmo tempo em que exercem um domínio sobre as formas através das quais os próprios agentes sociais (entre eles, os próprios jovens) se colocam em relação a seus problemas e às possibilidades de superá-los.

Palavras-Chave: Violência. Juventudes. Educação. Discurso. 
INTRODUÇÃO

Ao longo dos últimos séculos, filósofos e outros pensadores têm abordado a violência em diferentes sentidos: como motor da história, como mito social originário, como garantia final da coesão social, como mecanismo de dominação última sobre o controle das ideias, dos corpos e das populações, como evidência da ruptura do laço social, como condição para a opressão de classes, como consequência do desenvolvimento capitalista, como modo de subversão e transgressão, como modo de expressão da identidade, como manifestação de pulsões inconscientes, entre tantas outras acepções. Essa polissemia assinala a complexidade de um fenômeno que, ora sendo um mecanismo, uma causa, uma consequência, ora sendo um valor, um modo de relacionamento, uma possibilidade de ruptura e transformação social, evidencia uma condição humana ligada ao estabelecimento de relações de poder.

Por ser a violência um problema da sociedade como um todo, ela repercute na educação, e particularmente no meio escolar, de várias maneiras e por inúmeras razões. Ou seja, a escola e outras instituições educacionais refletem, em grande medida, a cultura, as normas, as políticas e leis governamentais, os documentos oficiais que existem no país, nos estados e nos municípios. Sobre a violência, em outras palavras, verifica-se intensa discursividade.

O fenômeno da violência, de grande complexidade, envolve questões sociais, políticas e econômicas. Neste artigo, tentamos examinar alguns dos aspectos específicos importantes desse fenômeno, sem ter a pretensão de abordá-lo em toda a sua complexidade. O primeiro diz respeito ao aporte das teorias sociais críticas e pós- críticas, contemplando principalmente o olhar antropológico-filosófico que enfatiza as construções discursivas sobre a violência, que nos ajudam a problematizá-la em relação a discursos oficiais da educação, particularmente a escolar. Também nos detemos em formulações que propõem o entendimento desse fenômeno em sua dimensão relacionada à própria condição do capitalismo, bem como suas manifestações subjetivas, que corresponderiam aos novos fundamentalismos emergentes. Um segundo aspecto abordado diz respeito à discursividade contida em mensurações oficiais da violência no contexto brasileiro. Essas formulações nos fornecem subsídios para, na terceira parte, trazer à luz algumas reflexões pautadas em pesquisa exploratória que envolveu uma análise documental.

Uma entre as inúmeras instâncias em que violência e educação se entrecruzam é em documentos oficiais específicos do campo da educação 
em saúde. Ao nos debruçarmos sobre alguns desses documentos - materiais publicados no marco do Programa de Saúde Escolar (PSE) -, desenvolvemos uma análise que pretende se posicionar criticamente sobre os discursos e as narrativas construídas nesses documentos.

\section{TENSIONANDO A VIOLÊNCIA}

Conforme indicam Minayo e Souza (1998), a "violência", como preocupação científica, tem transitado por diferentes áreas e campos acadêmicos, sendo um objeto de pesquisa sumamente complexo de ser abordado pelas formas convencionais de conhecimento, "em razão da carga de ideologia, preconceito e senso comum que invariavelmente o acompanha" (p. 514). Podemos afirmar, a partir de um entendimento amplo, que uma situação de violência supõe inerentemente uma relação unidimensional e instrumental entre pessoas (ou grupos de pessoas), na qual uma delas "perde o reconhecimento do seu papel de sujeito e é rebaixada à condição de objeto, mediante o uso do poder, da força física ou de qualquer outra forma de coerção" (MINAYO, 2013, p. 250). Dessa forma, a violência se coloca no centro das práticas sociopolíticas inerentes à relação do homem com o mundo e com os outros homens. Assim, a violência é conceituada, no sentido mausseano, ${ }^{1}$ como um fato social total a partir do "caráter tridimensional da experiência humana em sociedade", configurada sincronicamente pela dimensão histórica, pela dimensão fisiopsicológica e pela dimensão social (MINAYO, 2013, p.250).

Chauí (2011, p. 232) conceitua a violência como uma construção simbólica - tanto imaginária como ética e ideológica - que sustenta o autoritarismo social e político da sociedade brasileira, pois permite a naturalização de práticas objetivantes (criadas no período modernocolonial e mantidas na atualidade) que, em diferentes dimensões, reduzem determinados sujeitos "à condição de coisa", violando interior e/ ou exteriormente sua liberdade de ser e perpetuando "relações sociais de profunda desigualdade econômica, social e cultural".

Negri e Cocco (2005) também defendem a tese de que os Estados latino-americanos têm se constituído a partir de uma biopolítica racista e de guerra que atinge diferentes modulações a partir de uma base fundada no poder de extermínio dos grupos excluídos (negros, índios, mestiços). Segundo os autores, essa estratégia de poder (excludente e violenta) surge no período colonial e se mantém nas formas de organização e controle social moderno-contemporâneo. Os autores são concludentes quando afirmam que “a guerra na América Latina sempre foi guerra de extermínio das minorias 
(ou maiorias) étnicas dos escravos de origem africana, dos índios e, depois, das populações mestiças" (p.153).

Entre os desdobramentos civis dos efeitos biopolíticos, encontramos as estratégias discursivas monopolizadas pelos aparelhos midiáticos. Nos últimos anos, vimos assistindo ao fenômeno "espetacularizado" da violência, sendo esta uma estratégia de manipulação e construção da realidade que tem provocado a crença generalizada que "a violência" é um dos problemas sociais prioritários (CRUZ, 2015; CHAUÍ, 2011).

Chauí (2011) analisa esse fenômeno com base na tese de que o fascínio pela constante exibição de certas imagens "violentas" estaria ocultando uma outra violência real, mais profunda. A autora analisa o vocabulário empregado pelas mídias tradicionais (imprensa, TV) e denuncia como o uso de certos termos permite a legitimação de imagens distorcidas sobre os processos de violência social e política:

Fala-se em chacina e massacre para referir-se ao assassinato em massa de pessoas indefesas, como crianças, favelados, encarcerados, sem terra; fala-se em indistinção entre crime e polícia para referir-se à participação de forças policiais no crime organizado [...]; fala-se em debilidade das instituições políticas para referir-se à corrupção nos três poderes da república, a lentidão do poder judiciário, à falta de modernidade política; [...] (CHAUÍ, 2011, p.229-230, grifo da autora).

Segundo Chauí (2011), os processos de circulação massiva dessas imagens indicam a divisão entre "os grupos portadores de violência" (os que sofrem as chacinas e as massacres, vivem "na criminalidade", os que moram"no lugar onde a violência acontece") e "os grupos impotentes" que se localizam fora desses lugares e, ocupando os espaços institucionais de poder, são incapazes de combatê-la (CHAUÍ, 2011, p. 230, grifo da autora).

Assim, para a autora, a eficácia simbólica dessas imagens se sustenta por meio de "mecanismos ideológicos de conservação da mitologia da não violência" (p. 231). Segundo ela, esses mecanismos são: o de exclusão: "afirma-se que a nação brasileira não é violenta, e que se houver violência, esta é praticada por gente que não faz parte da nação (mesmo que tenha nascido e viva no Brasil)"; de distinção:"distingue-se o essencial e o acidental, isto é, por essência, os brasileiros não são violentos, a violência é acidental"; jurídico: a violência se limita aos campos da delinquência e da criminalidade, sendo o crime definido "como ataque a propriedade privada"; sociológico: a violência aparece como esporádica, atribuída ao fato social da "transição para a modernidade", quando os contingentes rurais migraram para as cidades; e de inversão do real: estratégias simbólicas de "produção de máscaras que 
permitem dissimular comportamentos, ideias e valores violentos como se fossem não violentos", por exemplo, o racismo paternalista branco como "proteção" para o "auxilio" dos negros inferiores (CHAUÍ, 2011, p. 231-232, grifo da autora).

Na mesma linha crítica, Minayo e Souza (1998, p. 522) indicam como "toda violência social tem, até certo ponto, caráter revelador de estruturas de dominação (de classes, grupos, indivíduos, etnias, faixas etárias, gênero, nações), e surge como expressão de contradições entre os que querem manter privilégios e os que rebelam contra a opressão".

Cruz (2015) e Žižek (2014) problematizam a violência como narrativa que serve à construção de uma sociedade do "medo". Segundo eles, subjetividades controladas pelo medo produzem identificações "fechadas"e fixam preconceitos para com a alteridade. Dessa forma, se estabelecem bodes expiatórios para os "problemas" sistêmicos, sendo essas estigmatizações culturais retroalimento para o acirramento dos circuitos de isolamento e afastamento entre "diferentes".

Žižek (2014, p. 45) afirma que essa reificação do terror da violência é mantida por uma ordem de Estado e um sistema político que funciona a partir de uma "biopolítica pós-política":

A "pós-política" é uma política que afirma deixar para trás os velhos combates ideológicos para se centrar, por outro lado, na gestão e na administração especializadas, enquanto a"biopolítica" designa como seu objetivo principal a regulação da segurança e do bem-estar das vidas humanas. É evidente que hoje as duas dimensões se sobrepõem: quando se renuncia às grandes causas ideológicas, tudo o que resta é a administração eficaz da vida... ou quase apenas isso. O que significa que, com a administração especializada, despolitizada e socialmente objetiva e com a coordenação dos interesses como nível zero de política, a única maneira de introduzir paixão nesse campo e de mobilizar ativamente as pessoas é através do medo, um elemento constituinte fundamental da subjetividade hoje. Por isso a biopolítica é em última instância uma política do medo que se centra na defesa contra o assédio ou a vitimização potenciais (ŽlŽEK, 2014, p. 45).

Nessa perspectiva, concordamos com o olhar antropológico-filosófico que enxerga a violência como um objeto de certa forma reificado, a partir da manifestação de diferentes discursos de poder: o científico, o tecnocrático, o escolar, o político, o religioso, o familiar, o comunitário, o midiático, o sanitário, etc. (RIFIOTIS, 2006). Trata-se de construções discursivas que instituem o medo - portanto, a ignorância e o afastamento preconceituoso - como forma de lidar com a alteridade. Dessa maneira, a violência se coloca como elemento 
imaginário que interpela as pessoas no nível da subjetividade, sendo aquele "fantasma, sem hora, nem lugar, que está no estranho da rua desconhecida, na noite escura. A violência é o caos, uma porta aberta para o caos; ela é a falta do limite, o imprevisível" (RIFIOTIS, 2006, p. 6). Violência como tudo aquilo que se impõe, que nos fere, que nos "faz mal", que destrói nossas fortalezas, que limita nossas possibilidades. Violência como "Não", como paralisação, como clausura de horizontes. Violência como elemento que divide, que afasta... uma estratégia de poder simbólico que captura as subjetividades e que, ao mesmo tempo, reforça outras formas de poder imperantes.

\section{A DISCURSIVIDADE SOBRE A VIOLÊNCIA NOS INDICADORES OFICIAIS}

Conforme Žižek (2014), a violência letal é um dos tipos mais visíveis e aterradores de violência subjetiva. Como explica o autor, a violência física e direta (o extermínio em massa, o terror, a guerra) junto à violência ideológica (racismo, incitação ao ódio, discriminação sexual) são as formas extremas da violência subjetiva, aquela que é "exercida por agentes sociais, indivíduos maléficos, aparelhos repressivos disciplinados e multidões fanáticas" ( $p$. 24). Mas, para o autor, além dessa violência subjetiva, existe uma outra, de caráter objetivo e sistêmico, aquela determinada pelo "autopropulsivo e enlouquecido" sistema capitalista globalizado, o qual funciona sobre"pessoas e objetos naturais em cujos recursos e capacidades produtivas se baseia a circulação do capital alimentando-se deles como uma parasita gigante" (p. 25). Segundo Žižek, existe uma conjunção entre os tipos extremos da violência subjetiva/visível e da violência objetiva/oculta. Citando Balibar (1997), o autor explica que:

Distinguem-se dois momentos opostos, mas complementares da violência excessiva: a violência sistêmica ou "ultraobjetiva", própria às condições sociais do capitalismo global, que implica criação "automática" de indivíduos excluídos e dispensáveis (dos sem-teto aos desempregados); e a violência "ultrassubjetiva" dos novos fundamentalismo emergentes, de caráter étnico e/ou religioso, em última instância, racistas (ŽlŽEK, 2014, p. 26).

Relatórios epidemiológicos, econômicos e demográficos recentes "preocupam-se" com os altos indicadores de violência letal entre os grupos jovens. Nesse tipo de documento, a violência é observada na sua manifestação visível subjetiva (ŽlŽEK, 2014), ou seja, como situação específica de interação na qual: 
[...] um ou vários atores agem de maneira direta ou indireta, maciça ou esparsa, causando danos a uma ou a mais pessoas em graus variáveis, seja em sua integridade física, seja em sua integridade moral, em suas posses, ou em suas participações simbólicas e culturais (MICHAUD, 1987 apud WAISELFISZ, 2012, p. 8).

Nessa compreensão da violência, pesquisas recentes incorporam ampliações conceituais, a partir de informações disponíveis pela implementação de novas categorias de registros. Assim, fala-se de situações de violência como aquelas experiências, práticas ou acontecimentos que, retroalimentando o círculo de vulnerabilidade/exclusão, vão contra o exercício de direitos, supondo um risco para a vida, a diminuição da qualidade de vida ou a limitação das possibilidades de desenvolvimento (WAISELFISZ, 2012).

No âmbito desse tipo de violência subjetiva, existem inúmeras práticas, muitas delas sutis, inclusive naturalizadas. No Brasil, uma fonte de informação inovadora tem sido o registro de notificações por violência doméstica, sexual e/ou outras violências (SINAN - SUS), que vem sendo aplicado pelo SUS desde 2009 de forma universal, obrigatória e compulsória em casos que envolvem crianças, adolescentes e mulheres, conforme estabelecem os estatutos legais vigentes. Segundo dados de 2011, os principais tipos de violência a que foram submetidas crianças e adolescentes vítimas atendidas no SUS foram: 40,5\% por violência física, 20\% por violência sexual, $17 \%$ por violência psicológica ou moral e $16 \%$ por negligência ou abandono (WAISELFISZ 2012). Essa multidimensionalidade do olhar sobre as situações violentas, apesar de apresentar um quadro complexo das diferentes formas da violência subjetiva, ratifica o foco na superficialidade da sua manifestação, legitimando visões e discursos que não problematizam aspectos mais amplos e estruturantes.

Por outro lado, a Secretária Nacional de Juventude, junto com o Ministério de Justiça do Brasil e o Foro Brasileiro de Segurança Pública, desenvolveu, a partir de 2013, novos indicadores para "medir" a violência. Interessante foi a modificação do Índice de Vulnerabilidade Juvenil à Violência (IVJ) para incorporar a dimensão da desigualdade racial. Dessa forma, o IVJ se atualiza, considerando os seguintes indicadores: violência entre os jovens, frequência à escola e situação de emprego, pobreza no município e escolaridade e desigualdade racial ${ }^{2}$ (BRASIL, 2015b). Conforme indica o relatório, em 2013, jovens negros entre 12 e 29 anos foram 18,4\% mais encarcerados e $30,5 \%$ mais vítimas de homicídios do que os jovens brancos. Já dados de 2012 constatam que "a prevalência de jovens negros serem mais vítimas de assassinatos do que jovens brancos é uma tendência nacional: 
em média, jovens negros têm 2,5 mais chances de morrer do que jovens brancos no país" (BRASIL, 2015b, p. 21). Para a cidade do Rio de Janeiro, esse risco relativo se apresentou similar $(2,3)$. Assim, na região Sudeste, a taxa de homicídios em 2012 foi 127\% superior para jovens negros (53,2\%) que para jovens brancos (23,5\%) (BRASIL, 2015b, p. 23).

Observamos no IVJ uma possibilidade de compreender a violência na interseção entre sua manifestação subjetiva/objetiva. Apesar do avanço na complexidade do indicador - no intuito de gerar informações que permitam descrever a multideterminação do fenômeno da violência -, consideramos importante mencionar que o IVJ ainda não recupera categorias relacionadas à participação e ao desenvolvimento integral dos jovens. As dimensões incluídas focalizam aspectos econômicos e sociais (pobreza, desigualdade, mortalidade, escolaridade) próprios às abordagens ligadas ao paradigma do Desenvolvimento Humano. De maneira nenhuma queremos dizer que esse paradigma não seja importante, mas chamamos a atenção para a necessidade de também considerar os aspectos culturais e políticos constitutivos das dinâmicas sociais dos jovens na contemporaneidade.

A informação oficial sobre jovens é, sem dúvida, imprescindível para contextualizar e "diagnosticar" certos aspectos populacionais (de biopoder) sobre esse momento da vida (o "juvenil"). Nesse sentido, é importante reconhecer que os censos e as informações estatísticas demográficas e sanitárias e demais formas de produção de "informação oficial" funcionam como tecnologias de governamentalidade que normalizam e regulam o que pode e tem valor para ser nomeado, classificado e mensurado (FOUCAULT, 1979). Como indica Anderson (1993), especificamente para os censos, esses dispositivos de geração de informação pública têm sido uma das estratégias de poder criadas e aperfeiçoadas pelo Estado Moderno a fim de condicionar/ controlar marcos de ação e representação identitária.

Nesse jogo, nessa luta por definir os critérios de mensurabilidade e ponderação oficial, pesquisas recentes sobre violência e juventudes, especificamente na cidade de Rio de Janeiro, têm focado na relação dessas temáticas com as de segurança pública, no marco da continuidade (e certa "legitimação social") das políticas de "Pacificação de Favelas". Essas iniciativas estatais têm optado pelo caminho do "combate à violência" a partir de estratégias de intervenção militar e policial em territórios considerados "conflitivos" (BUENO et al., 2015). Nesse sentido, se adotou uma medida de redução da violência proveniente do campo militar, implementada historicamente em contextos de pós-guerra e operativos para o restabelecimento da"paz". Pesquisas, seminários, relatórios de movimentos 
sociais, entre outros documentos públicos, têm colocado a necessidade de rever essas políticas de intervenção da força pública, pois, hoje em dia, os setores sociais mais desfavorecidos da cidade, além da violência do tráfico, do preconceito social, das dificuldades em acesso a serviços públicos, bens de capital e oportunidades de inserção social, são vítimas da violência policial cotidiana.

lasi (2014) chama a atenção para como a política de pacificação de favelas tem operado por meio de uma imposição cultural a partir da crença do mito civilizatório, agora militarizado. Nas palavras do autor:

A polícia que antes só reprimia agora protege e leva cultura, educação e decência. A polícia transforma-se em mediador de políticas públicas (sabemos que nem tão públicas assim) que, ao transformar a favela em um lugar de paz [...], levaria cultura para substituir os bailes funks da barbárie ou o hip hop da contestação, educação no antro de incultos e, finalmente, se tudo isso desse certo, chegaríamos à decência (IASI, 2014, p. 184).

Já analisando especificamente o lado objetivo da violência, retomamos Ribeiro (2015), que coloca a violência como problema de saúde determinado por certo tipo de organização social, na qual o Estado Moderno coloca-se como garantidor das "demandas e os interesses do poder produtivo dominante e hegemônico" (p. 59). No caso da cidade de Rio de Janeiro, as determinações sobre a saúde, a educação e a qualidade de vida presentes nas favelas"são fruto não de um acaso, não de um descaso, mas são o resultado de um modelo que preza e precisa em muitos momentos dessa organização social que vulnerabiliza socialmente grupos imensos da população" (RIBEIRO, 2015, p. 59). A organização social a que se refere o autor é o capitalismo dependente ou modernização conservadora, modelo caracterizado pela combinação entre tentativas de introdução de "elementos modernos do capitalismo" enquanto se mantém "elementos do mercantilismo colonial". Assim, podemos dizer que, no atual mundo globalizado, a configuração moderno-colonialista adquire novas dinâmicas, impactando nas contradições sociais que determinam a saúde, as oportunidades de educação, o desenvolvimento e as possibilidades de viver (ou morrer) de diferentes populações no Brasil. Como diz Žižek (2014), a ordem internacional do capital impacta regiões específicas do mundo,

Determinando a estrutura dos processos sociais materiais: os destinos de camadas inteiras da população e por vezes até mesmo de países podem ser decididos pela dança especulativa "solipsista" do capital, que persegue seu objetivo de rentabilidade numa beatífica indiferença ao modo como tais movimentos afetarão a realidade social (ŽlŽEK, 2014, p. 25). 
Segundo Ribeiro (2015), as políticas de segurança pública do capitalismo dependente estão relacionadas com a manutenção das relações de classe e poder, a fim de, entre outros aspectos: (i) limitar as possibilidades de organização coletiva, valorização cultural e conscientização identitária da classe trabalhadora na sociedade civil; (ii) aprofundar a brecha social e o individualismo próprio do mundo contemporâneo, que afasta diferentes setores da classe trabalhadora, através dos mecanismos de dominação ideológica criados e distribuídos pela mídia monopólica, e (iii) fortalecer o poder centralizador e autoritário de um Estado que utiliza seus mecanismos "últimos" (os da força militar e de policiamento de intervenção civil), como violências necessárias para manter "a ordem", ou seja, o status quo capitalista

Dessa forma, as políticas de segurança pública na cidade do Rio de Janeiro, apesar do seu propagandeado "sucesso" em comunidades específicas, provocam críticas solidamente fundamentadas. $O$ discurso da segurança pública que permeia as mídias e o senso comum incentiva uma construção mítica sobre a violência. Tal como indica Chauí (2011), são representações que carregam e operacionalizam estigmas e marcas intrínsecas aos sujeitos que moram em favelas, reproduzindo imagens que colocam a violência como algo que é"natural" da pobreza, próprio da "barbárie". Por meio desse mecanismo, ocultam-se possíveis leituras que permitam refletir sobre as estratégias de poder que sustentam processos políticos e sociais de manutenção das desigualdades (e das exclusões) necessárias para o desenvolvimento do capital, tendo como aliado o controle governamental por parte do Estado. Evidenciam-se assim os processos de inclusão e exclusão discursiva, em que os interditos são produto de um sistema de relações de poder/saber na sociedade. Foucault (1970) discute os variados procedimentos que regulam, controlam, selecionam e organizam o que pode e o que não pode ser dito, instituindo atributos de verdade ou não. Os discursos definem regimes de verdade que marcam fronteiras entre o verdadeiro e o seu contrário. Por essa linha, pode-se pensar que os discursos não descobrem verdades, eles as "inventam". A "ordem do discurso" nos faz refletir que o discurso sempre se produziria em razão de relações de poder.

Nessa perspectiva, consideramos importante refletir sobre aqueles processos que embasam as dinâmicas de produção e de circulação da cultura e trazem para a análise dos "discursos da violência" o papel do Estado Moderno como possessão, como autoridade, como complexo dispositivo de governamentalidade, que, apoiado no seu poder coercitivo do uso da força, reproduz e mantém violências sociais, políticas e simbólicas que repercutem tanto nos corpos como nas possibilidades e nos projetos de vida individuais e nas relações entre grupos e seu acesso ao poder. 


\section{A VIOLÊNCIA EM DOCUMENTOS DE EDUCAÇÃO EM SAÚDE: UMA ANÁLISE CRÍTICA}

No Brasil, programas governamentais articulados entre os setores de saúde e educação têm se preocupado, conforme as diretrizes internacionais, com o "combate à violência" entre os grupos jovens a partir da instauração do paradigma da "cultura de paz". O PSE foi instituído no Brasil em 2007 como política intersetorial entre Saúde e Educação. O objetivo seria atingir crianças, adolescentes e adultos escolarizados para a promoção da sua saúde e contribuir com uma educação integral. Um dos fundamentos da iniciativa é conformar redes de corresponsabilidade entre os serviços básicos de saúde e as instituições educativas nos municípios de todo o Brasil. Trata-se de uma estratégia de integração entre setores-chave para o exercício de direitos e a construção de cidadanias plenas.

No marco do PSE, em 2011, o Departamento de DST, AIDS e Hepatites Virais da Secretaria de Vigilância em Saúde do Ministério da Saúde (MS) publicou o fascículo Adolescentes e jovens para a educação entre pares: adolescências, juventudes e participação, no qual mostra a importância da promoção da participação juvenil para o desenvolvimento da cultura de paz e o combate à violência. Esse documento, alinhado com a perspectiva das políticas para a juventude impulsionadas no Brasil na conjuntura progressista do início do século XXI, destaca a importância de deixar de conceber os jovens como agentes problemáticos, recuperando sua potencialidade e sua agência para participar em espaços de tomada de decisões, desenho e execução de políticas (BRASIL, 2011).

Com respeito à sexualidade, o documento reconhece a relação necessária entre desenvolvimento integral, autonomia e situações "livres de violências":

[...] para que os(as) adolescentes e jovens possam aumentar a capacidade de identificar quais seriam as situações de risco no campo da sexualidade, é imprescindível que, além do conhecimento sobre formas de prevenção e proteção, eles(as) tenham autonomia em suas decisões e estejam livres, por exemplo, de todo e qualquer tipo de violência, sejam elas individuais, institucionais ou sociais (BRASIL, 2011, p.14).

Observa-se que, nesse documento, embora os jovens não sejam colocados como "problemáticos" e capazes de participar civicamente, são assumidos como vulneráveis a "riscos", reafirmando os discursos clássicos da epidemiologia social que criminaliza os sujeitos e marginaliza a juventude. Não obstante, no mesmo fascículo também se resgata o fator "contexto", 
passando a uma abordagem mais próxima à dos determinantes sociais da saúde e de outros condicionamentos culturais:

É preciso, também, considerar que a história de uma pessoa se desenrola em um determinado contexto familiar, cultural e social que dá significado e, ao mesmo tempo, constitui e define as características pessoais. Assim, por exemplo, uma garota negra que vive em um contexto de discriminação que tem dificuldade de acesso ao mercado de trabalho e que é desconsiderada por ser mulher pode estar mais vulnerável à violência racial e de gênero (BRASIL, 2011, p. 39).

Em termos gerais, podemos dizer que, no material em pauta, predomina uma visão sobre o jovem que enfatiza sua "vulnerabilidade individual", sendo a participação e o engajamento cívico uma das opções para o melhoramento da saúde. Porém, as possibilidades de dita "participação" não são problematizadas, no sentido de propor alguma reflexão crítica sobre como as "vulnerabilidades", entendidas como violências, são produzidas e qual o papel do Estado como garantidor de direitos. "Joga-se no jovem" a responsabilidade de conseguir garantir sua saúde, a partir do "afastamento das situações de risco"e de sua capacidade coletiva de "participar nas políticas públicas", sendo este último o desafio central do PSE. Observamos, assim, uma noção de violência que não contempla a dimensão sistêmica ou "ultraobjetiva" da qual fala Zizek (2014), própria às condições sociais do capitalismo global, que implica a criação automática de indivíduos excluídos e dispensáveis. A ordem discursiva que de alguma maneira se estabelece circunscreve o jovem a esse regime de vulnerabilidade, individual ou coletivo e, de algum modo, menospreza a capacidade de organização e de agenciamento que poderia ser criada por/com eles de outras maneiras e em outros espaços.

Outro documento importante publicado em 2015, também no marco do PSE, é o Caderno - Direitos humanos e cultura de paz. Com base no resgate dos direitos humanos reconhecidos pela Constituição Brasileira de 1988, propõe estratégias escolares para a construção da "cultura de paz", tendo como objetivo "gerar as transformações necessárias para que a paz seja o norteador de todas as relações humanas e sociais, no sentido de promover a convivência com a diferença e o respeito". A cultura de paz articula "mudanças que vão desde a dimensão dos valores, atitudes e estilos de vida até a estrutura econômica, jurídica e a participação cidadã", supondo um trabalho integrado a partir das "grandes mudanças desejadas pela maioria da humanidade justiça social, igualdade entre os sexos, eliminação do racismo, tolerância religiosa, respeito às minorias, educação e saúde integral, equilíbrio ecológico e liberdade política" (BRASIL, 2015a, p.3). 
No documento, a violência é vista como um fator que deve ser "prevenido", "reduzido", sendo essa responsabilidade compartilhada pelas funções públicas da Educação e da Saúde, em diálogo constante com as comunidades. A ênfase na responsabilidade do Estado como garantia dos direitos dos jovens é aqui assumida, sendo citadas as diferentes leis e marcos jurídicos que têm por objeto o desenvolvimento integral dos jovens.

Também se apresenta a necessidade de pensar a cultura de paz como um território de responsabilidades compartilhadas que, para um eficaz funcionamento, deve se articular em rede, somando atores comunitários e de outras áreas para gerar "ações integradas", a partir de uma visão ampliada (BRASIL, 2015a, p. 11).

Outra questão contemplada no documento são os "fatores protetores" e as "resiliências" dos jovens como atitudes, condutas, arranjos para mitigar ou "superar" situações de vulnerabilidade e violência, tanto dos estudantes como dos profissionais que trabalham no contexto escolar (BRASIL, 2015a, p. 23-24). Finalmente, o documento propõe estratégias pedagógicas (oficinas) para aplicar nas salas de aula, a fim de educar sobre violações aos direitos humanos, fatores de risco e proteção à violência, diversidades, cultura de paz e bullying (BRASIL, 2015a, p. 24-32).

Reconhecemos no documento um compromisso integral com o desenvolvimento da cultura de paz e a prevenção das violências. Nas oficinas propostas, fica clara a centralidade da cultura e dos determinantes sociais como condicionantes do desenvolvimento de "círculos de violência" ou "de paz". Nesse sentido, nas quatro estratégias de intervenção escolar sugeridas, evidencia-se a necessidade de focar os processos de prevenção das violências com base nas próprias realidades das comunidades.

Observamos no documento que a "paz" se coloca como contrária à violência do tipo subjetiva, em uma dimensão cultural que não reconhece o trabalho crítico e conflitivo para o desmascaramento das estratégias que mantêm as relações de poder na sociedade brasileira.

Lemos no documento uma ideia de "paz" moralizante, funcionalista e integracionista, que chama à "pacificação das juventudes" para a reestruturação do equilíbrio, da ordem, da homeostase, sendo a "violência", ora subjetiva, ora política, um "problema de desajuste" a ser "reconduzido". Nesse sentido, retomamos a tese de Fanon (1978), que diferencia a "violência do oprimido" da "violência do opressor", sendo a primeira justificada, como ato revolucionário, de contestação e transgressão humanizadora, diante da segunda, em estruturas sociais colonialistas. $O$ autor critica o discurso da não violência pelo fato de considerá-lo uma tentativa de consenso supérfluo, de 
debilidade política em face do poder absoluto do capitalismo colonialista. Como comenta Sartre, no prefácio do livro de Fanon (1978):

[...] se a violência tivesse começado esta noite, se nunca a exploração nem a opressão tivessem existido na face da terra, talvez a não-violência alardeada pudesse apaziguar a contenda. Mas se o próprio regime e até os vossos não-violentos pensamentos estão condicionados por uma opressão milenar, vossa passividade só serve para vos colocar do lado dos opressores (SARTRE, 1978, p. 17).

Entendamos que, para Fanon (1978), a violência dos colonizados - atualmente os sujeitos das classes populares, não brancas - não deve necessariamente manifestar-se como confronto armado, pois significa antes de tudo um processo de reconhecimento das condições econômicas, culturais e políticas que mantêm o colonialismo, sendo essa tomada de consciência o primeiro "despertar" para transformar as estruturas sociais, sem cair em novas configurações de opressão/dominação. Importante lembrar que o pensamento de Paulo Freire, principalmente em Pedagogia do oprimido (1987) e Educação como prática da liberdade (1967), também se apoia nessa diferenciação dos sujeitos coloniais conforme as relações de opressão e no mesmo projeto anticolonial de emancipação humana (MARTINS, 2012).

Para problematizar essa ideia de "paz", também recuperamos Chauí (2011), quando constrói a tese sobre o mito da "não violência" na sociedade brasileira e mostra como esse elemento imaginário permite a construção de relações sociais preconceituosas, extremamente violentas, que exercem o poder a partir da estigmatização e da culpabilização de certos grupos sociais, com o fim de perpetuar desigualdades políticas e econômicas. Nas palavras da autora: "O mito da não violência permanece [desde a sociedade colonial] porque graças a ele admite-se a existência empírica da violência e pode-se, ao mesmo tempo, fabricar explicações para denegá-la no instante mesmo em que é admitida" (p. 229).

Seguindo a noção foucaultiana de normalização, podemos dizer que, no documento, a "paz" se coloca como horizonte social natural-normal que se "desestabiliza" com diferentes episódios "violentos", os quais devem ser controlados por estratégias de poder disciplinar. .Assim, ensinam-se os estudantes, na escola, a serem pacíficos, sem estimular um processo de formação que leve à compreensão da historicidade e da multideterminação do fenômeno da violência. Nesse sentido, consideramos que chamar à "paz", como faz esse documento e muitos outros discursos oficiais, tem um viés acrítico e conservador, pois não dá lugar a que se problematize como situações de "paz" estão sustentadas por relações de poder que, além de monopolizar 
o uso da força repressiva nas mãos do Estado, escondem também aqueles mecanismos de poder produtivo, sobre as subjetividades, orientados à construção de sujeitos jovens "pacíficos", clausurados pela ameaça constante da violência (do tráfico, da criminalidade, da polícia, do mercado de trabalho, do ódio preconceituoso), sendo esse medo internalizado, autocontrole subjetivo.

\section{CONSIDERAÇÕES FINAIS}

A violência como narrativa, instituidora de "verdades", bem como as estatísticas produzidas pelo Estado e pelos diferentes "textos" no campo da educação em saúde aqui discutidos, constitui estratégias discursivas de saber-poder, monopolizadas pelos aparelhos midiáticos, que funcionam como norteadores dos campos de ação e das prioridades das políticas públicas, ao mesmo tempo em que exercem um domínio sobre as formas através das quais os próprios agentes sociais (entre eles os próprios jovens) se colocam em relação a seus problemas e às possibilidades de superá-los. Assim é que se efetua a legitimação de representações parciais sobre os processos de violência social e sobre as juventudes, reforçando o autoritarismo social e político.

Nessa perspectiva, de forma geral, é possível afirmar que, nas estratégias estatais analisadas, os entendimentos sobre "violência" são articulados sob uma ordem discursiva particular que amalgama discursos "legítimos" (midiáticos, jurídicos, econômicos, escolares, sanitários) com o estabelecimento de certas tecnologias governamentais, regulando práticas socioinstitucionais e configurando um regime de verdade específico que modela os desejos, os corpos e as representações dos sujeitos sociais. Assim, o discurso sobre violência atua por efeitos de verdade e de poder que permeiam a capilaridade social. O discurso científico-tecnocrático produz um tipo de saber que tem efeito sobre os corpos (individuais e sociais) pelo fato de definir perfis de vítima/agressor, tipologias, espaços e práticas violentas, comunidades violentas e "perigosas". Em outras palavras, o discurso oficial sobre "violência", sendo um dispositivo específico dentro do regime de verdade contemporâneo, produz efeitos nas práticas sociais, possibilitando e limitando a capacidade de questionamento e transgressão dos grupos populares.

Finalmente, consideramos que todas essas estratégias de controle pelo Estado para o gerenciamento e o monitoramento das juventudes, principalmente as faveladas, periféricas, excluídas, dificultam projetos de transgressão em sociedades, já por si mesmas, excludentes e violentas. 
Entretanto, não podemos ignorar a dinâmica complexa que caracteriza o campo em que o saber/poder atua, o campo da prática. Neste, as diversas instituições - educacionais, de saúde etc. - e os sujeitos, antes de meramente espelhar os discursos oficiais, os recontextualizam, através de processos de normalização, reforço, modificação e resistência, ou seja, eles não devem ser entendidos como algo que acontece a distância, ou acima das práticas (BOWE; BALL; GOLD, 1992).

\section{VIOLENCE, YOUTH AND EDUCATION: SIGNIFYING DISCURSIVE CONSTRUCTIONS}

ABSTRACT: The article relies on the framework of socio-anthropological and post structuralism theories to discuss / stress the notion of violence, evidencing it as narrative, establishing "regimes of truths". In this same perspective, it approaches the statistics produced by the State and analyzes some "texts" in the field of health education, characterizing them as discursive strategies of knowledge-power, monopolized by the media apparatus, which function as guiding the fields of action and public policy priorities, while at the same time exercising control over the ways in which the social actors themselves (among them young people themselves) stand in relation to their problems and possibilities of overcoming them.

KEY words: Violence. Youth. Education. Discourse.

\section{VIOLENCIA, JUVENTUDES Y EDUCACIÓN: UNA LECTURA SOBRE CONSTRUCCIONES DISCURSIVAS}

RESUMEN: A partir de teorías socio-antropológicas y post-estructuralistas se discute/ tensiona la noción de violencia, evidenciándola como narrativa, instituyente de "regímenes de verdades". En la misma perspectiva, se abordan las estadísticas producidas por el Estado y se realiza un análisis de "textos" en el campo de la educación en salud, caracterizándolos como estrategias discursivas de saber-poder, monopolizadas por los aparatos mediáticos, que funcionan como orientadores de los campos de acción y de las prioridades de las políticas públicas, al mismo tiempo que ejercen un dominio sobre las formas a través de las cuales los propios agentes sociales (entre ellos los propios jóvenes) se posicionan frente a sus problemas y posibilidades de superarlos.

Palabras claves: Violencia. Juventudes. Educación. Discurso. 


\section{NOTAS}

1 Conceito trabalhado pelo antropólogo M. Mauss em seu livro, Sociologia e antropologia $(1974$, v. 1).

2 Desigualdade racial como indicador é expressa pela "razão entre a taxa de mortalidade violenta de jovens negros e a taxa de mortalidade violenta de jovens brancos" (BRASIL, 2015, p.11).

\section{REFERÊNCIAS}

ANDERSON, B. Comunidades imaginadas: reflexiones sobre el origen y la difusión del nacionalismo. México: FCE,1993.

BOWE, R.; BALL, S.; GOLD, A. reforming education \& changing schools: case studies in policy sociology. London: Routledge, 1992.

BRASIL. Ministério da Saúde. Departamento de DST, AIDS e Hepatites Virais da Secretaria de Vigilância. Adolescentes e jovens para a educação entre pares. Brasília, 2011. Disponível em: < http://www.aids.gov.br/publicacao/adolescentes-e-jovens-para-educacao-entre-pares-spe>. Acesso em: 8 out. 2016.

Secretaria Nacional de Juventude (SNJ), Ministério Da Justiça (MJ) e Fórum Brasileiro de Segurança Pública (FBSP). Índice de vulnerabilidade juvenil à violência e desigualdade racial 2014. Brasília: 2015. Disponível em: <http://unesdoc.unesco.org/ images/0023/002329/232972POR.pdf> Acesso: 18 out 2018.

- Ministério da Saúde. Ministério da Educação. Programa Saúde Escola. Caderno - Direitos humanos e cultura de paz. Brasília. 2015b, versão preliminar. Disponível em: <http://189.28.128.100/dab/docs/portaldab/documentos/caderno direitos humanos.pdf >. Acesso em: 5 jan. 2017.

Ministério de Justiça. Secretaria Nacional da Juventude. Fórum Brasileiro de Segurança Pública. Índice de vulnerabilidade juvenil à violência e desigualdade racial. Brasília, 2015a. Disponível em: <http://www.unesdoc.unesco.org/ images/0023/002329/232972POR.pdf>. Acesso em : 10 nov. 2016.

BUENO, L. B. et al. (Org). Saúde e segurança pública: desafios em territórios marcados pela violência. Rio de Janeiro: Cooperação Social/Fiocruz, 2015.

CHAUÍ, M. Sobre a amizade - introdução à "ética e violência". In: PAOLI, M. C. Diálogos com Marilena. São Paulo: Editorial Barcarolla: Discurso Editorial, 2011. p. 212-244, parte IV.

CRUZ, R. R. Miedo al otro: comunicación, poder y representación en una contemporaneidad sobresaltada. Anagramas, v. 1, n. 1, p. 51-66, 2015.

FANON, F. Os condenados da terra. Trad. José L. de Melo. Rio de Janeiro: Civilização Brasileira, 1978. Disponível em: <https://kilombagem.net.br/wp-content/uploa- 
ds/2015/07/Os condenados da_Terra-Frantz-Fanon.pdf $>$. Acesso em: 15 jun. 2017.

FOUCAULT, M. Microfísica do poder. Org. e ver. Roberto Machado. 11. ed. Rio de Janeiro, Graal, 1979. Disponível em: < http://petletras.paginas.ufsc.br/files/2017/03/foucault-microfisica-do-poder.pdf> . Acesso: 30 maio 2017.

. A ordem do discurso. 13. ed. São Paulo: Loyola, 1970.

FREIRE, Paulo. Educação como prática da liberdade. Rio de Janeiro: Paz e Terra. 1967. Disponível em: <http://www.dhnet.org.br/direitos/militantes/paulofreire/livro_freire_educacao_pratica_liberdade.pdf> . Acesso em: 15 de jul. 2016.

. Pedagogia do oprimido. 17. ed. Rio de Janeiro: Paz e Terra, 1987. Disponível em: <https://groups.google.com/forum/\#!topic/computacao-iftm4/XXIFm66nxBE> Acesso em: 5 de jul. 2016.

IASI, M. Posfácio. Violência, esta velha parteira: um samba-enredo. In: ŽIŽEK, Slavoj. Violência. Seis reflexões laterais. Trad. Miguel Serras Pereira. São Paulo: Boitempo. 2014. p. 171-189.

MARTINS, P. Confluencias entre el pensamiento de Frantz Fanon y el de Paulo Freire. El surgimiento de la educación popular en el marco de la situación colonial. Educação. Revista do Centro de Educação, v. 37, n. 2, 2012.

MAUSS, M. Sociologia e antropologia. São Paulo: EDUSP, 1974. v. 1.

MINAYO, M. C. Violência e educação: impactos e tendências. Revista Pedagógica, vl. 15, n. 31, p. 249-264, dez./jul 2013.

MINAYO, M.C. de S.; SOUZA, E.R. de. Violência e saúde como um campo interdisciplinar e de ação coletiva. História, Ciências, Saúde, v. 4, n. 3, p. 513-531, 1998.

NEGRI, A., COCCO, G. Glob (AL): biopoder e luta em uma América Latina globalizada. Rio de Janeiro: Record, 2005.

RIBEIRO, P.C. de C. Saúde e segurança pública no contexto do capitalismo dependente. In: BUENO, L. B. et al. (Org.). Saúde e segurança pública: desafios em territórios marcados pela violência. Rio de Janeiro: Cooperação Social/Fiocruz, 2015, p. 59-68.

RIFIOTIS, T. Nos campos da violência: diferença e positividade. Laboratório de Estudos das Violências (LEVIS). Departamento de Antropologia Social. Universidade Federal de Santa Catarina, 2006. Disponível em: <https://www.researchgate.net/publication/266878367_Nos_campos_da_violencia_diferenca_e_positividade $>$. Acesso em: 18 out. 2018.

SARTRE, J. P. Prefácio. In: FANON, F. Os condenados da terra. Trad. José L. de Melo. Rio de Janeiro: Editora Civilização Brasileira, 1978. p. 1-21, 1978. Disponível em: <https:// kilombagem.net.br/wp-content/uploads/2015/07/Os_condenados_da_Terra-Frantz-Fanon.pdf > . Acesso em: 15 jun. 2017. 
WAISELFISZ, Julio J. Mapa da Violência 2012: crianças e adolescentes do Brasil. Rio de Janeiro: Centro de Brasileiro de Estudos Latinoamericanos (CEBELA), FLACSO, Brasil, Área de Estudos sobre a violência, 2012. Disponível em: <http://www.mapadaviolencia.org.br/pdf2012/MapaViolencia2012_Criancas_e _Adolescentes.pdf >. Acesso em: 24 set. 2016.

ŽlŽEK, S. Violência. Seis reflexões laterais. Trad. Miguel Serras Pereira. São Paulo: Boitempo. 2014.

Valentina Carranza Walhmuller: Graduada em Licenciatura em Comunicación Social - Universidad Nacional de Córdoba - Argentina. Doutoranda no Programa de Pós-Graduação em Educação em Ciências e Saúde (UFRJ). Linha de pesquisa: Mediações socioculturais em educação. Temas de pesquisa: juventudes, comunicação, educação e cultura.

E-mail: cw.valentina@gmail.com

Vera Helena Ferraz de Siqueira: Doutora em Educação pela Columbia University, professora no Programa de Pós-Graduação Educação em Ciências e Saúde/ UFRJ. Atua em pesquisa, ensino e extensão com ênfase nos seguintes temas: políticas de identidade e formação profissional; educação em saúde; relações de gênero, raça/etnia e educação; mídia e educação.

E-mail:verahts@yahoo.com.br

Andrea Costa da Silva: Doutora em Educação em Ciências e Saúde (NUTES/UFRJ), docente do Programa de Ciências Aeroespaciais/ UNIFA. Atua em pesquisa, ensino e extensão com ênfase nos seguintes temas: educação em saúde, estudos culturais e educação, gênero e sexualidade, literatura e educação.

E-mail: acostadasilva@gmail.com 